\title{
Naturalising electricity in Greek advertising: transitions between past and present in identity crafting, 1954-62
}

Selling this invisible, odourless, colourless, potentially dangerous and expensive form of energy (electrical power) has been a challenge throughout the developed world since the late nineteenth century. Greece's nation-wide electrification in the 1950 s was closely associated with the overriding post-war concept of progress and a modern, civilised way of life. Convincing people living outside of the metropolis of the essentiality of the new form of energy was very important as general mentalities concerning fear of using this new power, as well as its perceived superfluous and luxurious connotations, had to be argued against. This paper looks at the themes employed in print advertising commissioned by two competing electrical provision companies to convince the Greek public to use this new, abstract, and technologically advanced commodity. Although both companies started by showing their industrial profile through photographs, and generally, shared common themes, they soon developed their own sophisticated, creative advertising solutions choosing distinct representation techniques: photography and illustration respectively. Their divergence raises questions with respect to the role and relevance of (new and old) media in promoting electricity a product of modernity writ large, and ultimately, in addressing the country's post-war identity.

print advertising, cultural heritage, technical civilisation, visual media, national identity

\section{Introduction}

\section{Electrifying post-war Greece}

After the Second World War and the Greek Civil War that ended in late 1949, Greece was left in ruins, bitterly divided with its economic and pre-war industrial infrastructure largely destroyed. Electrification occupied a central place in the country's broader postwar reconstruction and modernisation with the contribution of the United Nations Relief and Rehabilitation Administration and the Marshall Plan (Pantelakis 1991: 370). With the exception of the private Electrical Company Athens-Piraeus (ECAP, est.1929/30), based in Athens and known as the 'English company', the operation of the approximately four hundred electricity companies around the country was thought of as ineffective for the industrialisation of the country and domestic use (Pantelakis 1991: 392-3). Even though, Greece's electrification programme was initiated in 1889, it is the year 1950 that is considered a turning point in the history of the electrification of the country, with the foundation by the state of the Public Power Corporation (PPC), which by 1962 monopolised the market (Tsotsoros 1995: 82). 
theme 3

identity

Figure 1.

PPC advertising by Rado (left: 1957, middle: 1961, right: 1961). strand 1

design process and pratice

From 1954 to 1962 PPC and ECAP engaged in fierce promotional competition with each other through a range of publicity strategies including advertising, showrooms, exhibitions, fairs, photo-essays, posters, and educational films. In their early advertising campaigns, both companies projected their industrial background through photographs of factories, dams, stations and close-up frames of the machinery, including turbines, generators and pylons. This photographic approach was taken when in reality photography, until at least the 1960 s, was not a common medium of representation in Greek advertising. This was mainly due to its costly reproduction process and the limited printing requirements of some periodicals, but also due to the predominance of artists (painters) -rather than photographers- in the graphic design and advertising sector. However, after 1957, their approach diverged in terms of manipulation of themes and use of media. The sections below deal specifically with the advertising promotion (in total 72 advertisements: 38 for PPC and 34 for ECAP) in popular magazines and trade journals, and analyses the themes and visual media employed for the purpose.

\section{Drawing the past and the present (PPC)}

\subsection{Democratising electricity}

Greek society at the turn of the 1950 s was one of high social inequalities, and, despite the prosperity and economic growth that was observed disparities prevailed (Close 2002: 58-82). By 1950 just 30 per cent of the country was electrified, primarily the capital (Athens), which represented 80 per cent of this total (Kassianou 2006: 14; Tsotsoros 1995: 112). Public need for social and economic justice was addressed in slogans such as 'Electrification for all Greeks'. As seen in a 1957 advertisement (Fig. 1, left), the motto 'Light for All' in archaic-style lettering and in the old linguistic idiom, seems to come out of the mouth of the fair-minded god Zeus - an order for PPC to execute. Zeus' familiar identity and status as a 'father' figure in Greek society helped naturalise and neutralise the threatening aspects of this unknown, new and potentially dangerous electrical power. Here, the past promised democratic sharing of a commodity enjoyed until then by the few, and mostly in the metropolis.
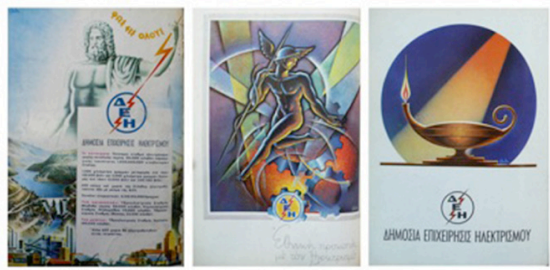

Most importantly, this kind of promotion echoed the parable of the 'democracy of goods', which has been the most pervasive of all advertising tableaux of 1920 America (Marchand 1985: 217-22), according to which the wonders of modern mass consumption, production and distribution enabled every person to enjoy society's most significant pleasures, conveniences or benefits. In the Greek case, by implicitly defining democracy in terms of equal access to electricity rather than as a political concept per se, these visual clichés offered Greeks a vision of their society as one of incontestable fairness and equality in their everyday lives.

\subsection{Integrating the past with the present}

Besides Zeus, other mythological figures were also employed. Yet these were not included merely for their symbolic qualities as representations of a glorious past, but in 
relation to present and contemporary technological developments. Hermes, the god of commerce, identified by his winged cap, is pictured overseeing progress driven by PPC (Fig. 1, middle). In a complex of colourful diagonal shapes and cogwheels, PPC appears to hold a leading part in this mechanical nexus. Thus, the new prospering Greece, as voiced in the accompanying slogan ('National prosperity with Electricity'), was developing into an industrial and modern nation complimenting its agricultural and rural character.

In fact, the inclusion of the present in the past and vice versa was a favourite topic in PPC print advertising that was created mostly by 'Rado', Petros Radovitis or Radoviç (of Slavic origin), an indexed maquettiste and an employee at PPC's Press and Public Relations Office (est. 1956). For example, a diagonally positioned beam of light (similar to stage lighting) illumined the subject, whether a mythological persona, an ancient pillar, or an oil lamp (Fig. 1, right), which has once been juxtaposed with the electrical switch. These designs implied that the present had not broken with the past, but instead would supply better versions of experiences similar to those of the past offering a smooth transition between the two conditions.

However, the use of the past or tradition in the pictorial context was not a Greek peculiarity. It was also recorded in the Japanese context for the promotion of electrical goods in the 1950s. The latter case made use of the 'three sacred treasures' (a sword, jewels, a mirror) advertising strategy drawn from Japanese mythological antiquity (Yoshimi 1999). It was also used in General Electric's marketing of the Mazda mark in the early twentieth century, which was initially associated pictorially with the sun as a familiar part of life, and later on, with the rise of Orientalism as a popular merchandising theme in America, electric light was naturalised through fantasies of a pre-industrial Orientalist culture (George 2003: 62-71). It is suggested thus in the Greek case too the concepts of tradition and modernity are not necessarily antithetical, and the past played a crucial enabling role in becoming modern.

\subsection{The autonomous, technologically-driven Greece}

Besides the symbol of lightning used in the PPC trademark, an object used prominently as a signifier of electricity in PPC's promotion was the pylon - the steel tower supporting high-tension wires - as was the case in the international scene. For instance, in 1939, the Swiss poster artist Peter Birkhäuser drew a pylon (the 'Paillard' tower) in complete isolation on a dark background (Fig. 2, top right). And in later times, posters for the French electricity company Electricité de France (EDF), designed by the French poster artists Bernard Villemot and Mario Tauzin, used the pylon as a central reference in painterly and graphic representations.

In Greece, in an effort to monumentalise technical civilisation, pylons were presented as the 'new columns' replacing in a way the actual pillars of Greece's classical architecture. Models of pylons could also be seen in the PPC showroom and in the company's pavilion at the Thessaloniki International Fair, thus appropriating this modern icon for private space and neutralising the more threatening aspects associated with its rapid invasion of the public environment (Meikle 1995: 143-67). In one advert (1961), the four bases of a giant pylon tower were positioned on a stylised map depicting the four parts of the country, thereby embodying the company's mission to provide power on a national scale (Fig. 2, left). The whole image of Greece under this pylon of 'heroic proportions' (Marchand 1995: 265-7) transmitted the idea of a progressive and strong country, a statement eloquently voiced by the slogan, 'In a Greece that moves on... Electricity gives power'. 
theme 3

identity

Figure 2

PPC advertising by Rado: left: 1961; middle: L. Beall, 1937; top right: $P$. Birkhäuser: 1939; below right: Cassandre, 1925 strand 1

design process and pratice
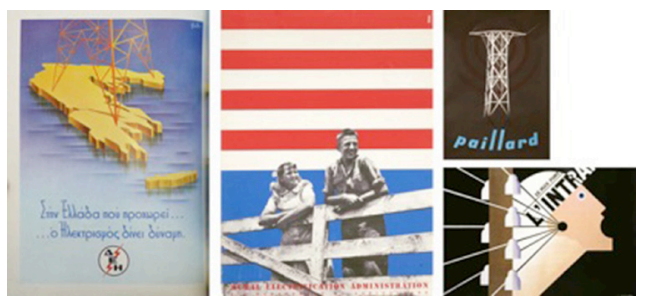

In this strongly symbolic image, Greece is portrayed as an independent island amid the calm waters of the Mediterranean. Disconnected from its Balkan neighbours in the north, or in fact from any other nearby countries, Greece, as seen from a bird's eye view, seems to declare autonomy and a sense of independence. In fact, the idea of dependency, particularly, on international resources, was an issue in the national press and political discourse, affecting both internal and foreign affairs (Tsotsoros 1995: 94; KaltsogiaTournaviti 1993: 659-60). It was reported that a day before the Second World War erupted, 95 per cent of the electrical power consumed in Greece came from imported coal and oil (Pantelakis 1991: 446). Therefore, the notion of independence was rooted in strong political reasoning, for enhancing the power autonomy of the country (Tsotsoros 1995: 59, 87, 379). Cheap energy could be achieved by the use of indigenous natural resources and the creation of a united, centralised national network (Pantelakis 1991: 379). By using national resources for electrification, it was hoped that Greece would no longer depend upon foreign powers and could declare 'independence' from these interests ('And there was Light': 1955; Mingos 1960: 27-82).

Parallel to this, there were further implications related to the country's profile. The image of Greece as a country where technology, through the visual reference of the pylons, was tightly and securely grounded, brought in an alternative identity. The notion of a technologically and electrically driven nation came in rigid contrast to its celebrated ancient stereotype that featured most prominently in contemporary promotion of Greece by the Greek Tourism Organisation. Indeed, technology was not only neutralised and naturalised in the local context, but was treated as the underpinning of modern Greek technical civilisation.

Design-wise, the over-sized, cut-out image of a pylon resembling the Surrealist technique of the French artist Cassandre for the famous Marocaine cigarettes (1935), or of the Swiss Josef Müller-Brockmann's poster designs (1955), created an unconventional space and perspective, unique and novel in Greek mainstream advertising. Yet, the pictorial tools used by Rado were highly descriptive, realistic and illustrative and, in some sense, in contrast with those experimental posters by well-known designers and artists who worked for the promotion of electricity, namely Man Ray (for EDF in the 1920s), and Lester Beall (for the American Rural Electrification Administration, 1937-1941), whose work was characterised by graphic simplicity, with flat, unfussy illustrative elements (Fig. 2, middle).

Even though, images close to the electricity sector (e.g., electrical switches by 'Heytum', a photograph of a pylon by the American company T.V.A., and a poster of 1925 by Cassandre for the Paris newspaper L'Intransigeant) (Fig. 2, below right) were cited in the Athens-based art journal Zygos (Michelis 1959a/b), and evidence from the PPC Archive shows that many posters for the Health and Safety Department were nearly exact copies of material produced by foreign institutions (such as the National Safety Council (Chicago), the Texas Power and Light Company, the EDF, and by a German safety provision body), Rado's descriptive style represented a divergence from contemporary international graphic design on the subject. 


\section{Refocusing the past and present (ECAP)}

\subsection{From Classicism to the modern city}

While PPC was illustrating the technologically advanced Greece at the time, ECAP adverts included photographs of the most important and most visited ancient sites in Athens through careful perspective and illumination (Fig. 3, left). These monuments thus became the object of the photographic lens and ultimately the viewer. In dealing with the promotion of electricity since the 1930 (in the case of ECAP), Greek photographers (among them D. Harissiadis, K. Balafas, and E. Serafis) are argued to have used a mixture of modernism and conservatism - a mix that 'combined personal realities and the need to achieve particular goals for the purpose of propaganda' (Kassianou 2006: 46-47). And although they 'were deeply engaged in structuring the new society', photographic historian Nina Kassianou has claimed that 'they were not influenced by a powerful ideology [the 'New Vision'] like their pioneering European and American counterparts' (Ibid). The promotion of the cultural heritage of Greece through the realistic lens of photography was prevalent in ECAP's campaigns. The subject was not one of inspiration but, rather, a conventional subject matter of lyrical and grandiose quality exploited in travel paraphernalia since the nineteenth century. Peter Pollack, director of photography at the Chicago Art Institute, commented on this topic in 1957, 'Greek photographers, like Greek architects and artists in general, have constantly in front of them an insuperable obstacle of convention, the artistic achievements of the ancients' (Pollack 1957: 13-15). In short, Pollack addressed the so-called 'weakness' of many Greek artists, and particularly photographers, to surpass the past and project the present.
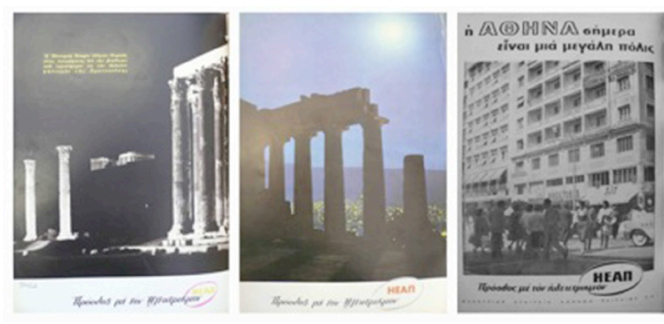

Figure 3 .

ECAP advertising (left: 1957, photo: E. Serafis, middle: 1959, right: 1960)

The focus, however, started to shift. The photographer began to shoot from the site location towards the illuminated city by night, which has now become the new subject matter (Fig. 3, middle). Beyond the historical rhetoric expressed in the new series of photographically based advertisements, ECAP promotion emphasised the excitement of life in a big city and inaugurated a new phase in the company's connection with its audience. In 1960 the focus of the company's promotion shifted from the ancient past to the lively present and city life, with two adverts featuring the city of Athens in black-and-white photographs and supported by the slogan 'ATHENS is now a big city'. The second advertisement of the series showed people in an urban setting; an aspiration for a modern way of life that one only a few privileged Athenians could enjoy (Fig. 3, right). This spontaneous, outdoor photography resembled closely the already fashionable social documentary or outdoor landscape approaches in American photography in the 1950 s and 1960s. Within a threeyear period (1957-1960), the emphasis in ECAP advertising had moved from technology to end product and the benefits of electrification for the urban environment. In this case too, ECAP challenged the archetypal image of Greece. A country with a world-acclaimed ancient past was now installed in a contemporary technological (electricity-driven) and urbanised present. 


\section{Conclusion}

Far from being a case study of design consistency and regularity, the promotion of electricity in post-war Greece through the plethora of themes and representational means reveals the struggle to introduce a new product and make it less threatening and, indeed, indispensable for Greek society. In a relatively short period of time, the naturalisation of this modern material good was achieved by mixing ancient culture with elements of technical civilisation and with the use of different visual tools; illustration and photography. While ECAP made use of the new medium of photography to offer new visual narratives of ancient sites and busy urban streets, PPC preferred a more conventional and familiar to the public medium that aided creation of a nostalgic, dramatic, fictional atmosphere, making the tool of representation a naturalising factor, or, in a way, the message itself (McLuhan: 1964/1967). The freedom and flexibility in insisting on illustration instead of the more expected, or fashionable one (photography) in addressing a modern commodity shows that the 'modern' was a factor of constant negotiation. Electricity, a modern subject per se, was the product of negotiation and inclusion, a balancing between the new and the old, past and present. Nevertheless, in both cases, Greece acquired new identities that at times intersected, overlapped or transposed its antiquarian or contemporary agricultural façade.

\section{References}

'And There Was Light!', Ikones (9) December 1955, pp. 30-33. Close, D. (2002) Greece Since 1945, Great Britain: Longman. Gallant, T.W. (2001) Modern Greece, London: Arnold. George, L., (2003) 'The Sun's Only Rival', Design Issues, vol. 19, no. 1, pp. 62-71. Kaltsogia-Tournaviti, N. (1993) 'The Post-War Greek Society and the Way to the Institutional-Political Modernisation', in The Greek Economy during the First Post-War Period (1945-1967) Conference Proceedings, Saki Karagiorga Foundation, 24-27 November. Karapostolis, V. (1983) Consuming Behaviour in Greek Society, 1960-1975, Athens: National Centre for Social Research.

Kassianou, N. (ed.) (2006) Pioneers of the Technical Civilization, Thessaloniki:

Photography Centre/Thessaloniki Museum of Photography.

Marchand, R. (1985) Advertising the American Dream, London: University of California Press. McLuhan, M. (1964) Understanding Media: The Extensions of Man, Canada: McGraw-Hill. McLuhan, M., Fiore, Q. (1967) The Medium is the Massage, London: Penguin.

Meikle, J.L. (1995) 'Domesticating Modernity' in Kaplan W. (ed.) Designing Modernity, London: Thames \& Hudson.

Michelis, P.A. (1959) 'Industrial Aesthetic and Abstract Art', Zygos, Vol. A (38) January, pp. 29-36, and Vol. B (39) February, pp. 27-41, 51.

Mingos, V. (1960) 'The First Ten Years', Architektoniki (22-23) July-October, pp. $27-82$. Pantelakis, N.S. (1991) The Electrification of Greece, Athens: National Bank of Greece Historical Archive.

Pollack, P. (1957) 'Greek Photographers in Exhibitions Abroad', Zygos, Vol. 3, №. 6

December, pp. 13-15.

Remington, R.R. (1996) Lester Beall, New York: W.W. Norton \& Co.

Tsotsoros, S.N. (1995) Energy and Development in the Post-War Period, Athens:

Neohellenic Research Centre.

Yoshimi, S. (1999) 'Made in Japan', Media, Culture and Society, Vol. 21, N. 2, pp. 149-171. 